\title{
Small Time and Space Measurements of the Mean Rainfall Rate Made by a Gage Network and by a Dual-Polarization Radar
}

\author{
Mohamed Messaoud and Yves B. Pointin \\ LAMP/OPGC (UA/CNRS), Université Blaise Pascal, Clermont-Ferrand, France
}

(Manuscript received 23 May 1989, in final form 7 December 1989)

\begin{abstract}
Small time (1 to $15 \mathrm{~min}$ ) and space $(0.5$ to $1.5 \mathrm{~km}$ ) measurements of the mean rainfall rate have been made within $10 \mathrm{~km}$ from a dual-polarization radar, during several widespread or convective precipitation events. At first, the time and space characteristic scales of the gage and of the radar data are evaluated in order to find the minimum time interval $\Delta t$ and spatial resolution $\Delta x$ for which the mean rainfall rate values have a large enough statistical significance. Then the quantitative comparisons are made between the mean rainfall rate $R_{G}$ deduced from the gage data and that deduced from the radar measurements, either without $\left(R_{Z}\right)$ or with $\left(R_{D}\right)$ using the differential reflectivity $Z_{D R}$ values.
\end{abstract}

\section{Introduction}

Urban hydrology of most big metropolises requires the real-time estimation of the mean precipitation over small drain catchments, of areas of a few tens of square kilometers, with a time resolution $\Delta t$ better than 5 to 10 minutes. Although a raingage network may be difficult and very expensive to set up and operate in these big cities, it can give the direct rainfall rate measurement with the required resolution, provided that its density is large enough (Huff 1970). Indeed, the gage spacing must be smaller than the spatial variation of the rainfall (Silverman et al. 1981) for the required time interval $\Delta t$ of the estimation. Therefore, for very short time intervals, the gage spacing must be smaller than the size of convective cells; namely, it should be of the order of one kilometer. In the experiment described in the next section, 14 one-minute resolution raingages have been set up over a $25 \mathrm{~km}^{2}$ area, giving a mean gage spacing of $1.5 \mathrm{~km}$. The first goal of this paper is to evaluate the smallest time interval $\Delta t$ and spatial resolution $\Delta x$ (Eddy 1976) for which the true mean rainfall rate $R_{m}$ can be "significantly" estimated from the gage data. This evaluation, and the criteria used, are described in the third section. The maps of the mean rainfall rate field, interpolated from the gage data, are discussed in section 4.

The time and space resolutions required by urban hydrology can also be provided by meteorological radars that lead to an estimation of the rainfall rate from the reflectivity measurements. Numerous works have

Corresponding author address: Dr. Yves Pointin, LaMP/OPGC, 12, Avenue des Landais, 63000 Clermont-Ferrand, France. been devoted to the radar estimation of the rainfall rate (Wilson and Brandes 1979; Doviak 1983; Barnston and Thomas 1983; Austin 1987; Creutin et al. 1988, among many others) for time intervals generally greater than 1 hour. For short time intervals, however, the reflectivity $Z$ of the cloud is only weakly related to the rainfall rate, because the drop size distribution $N(D)$ shows quite a large time variability (Seliga et al. 1986; Chandrasekar and Bringi 1987; Illingworth et al. 1987). A dual polarization radar (Seliga and Bringi 1976) measures, for the same cloud volume, two independent reflectivities, namely the horizontal reflectivity $Z_{H}$, similar to the reflectivity $Z$ measured by any conventional radar, and the differential reflectivity $Z_{D R}=Z_{H}$ $-Z_{V}$, which is mainly related to the mean diameter of the drop size distribution. Due to this supplementary information on the drop size distribution $N(D)$, theoretical and experimental works (Seliga and Bringi 1976; Hall et al. 1980; Seliga et al. 1981; Bringi et al. 1982; Goddard et al. 1982; Jameson 1983; Ulbrich and Atlas 1984; Feingold and Levin 1987; Sachidananda and Zrnic 1987) have shown that a better estimate of the rainfall rate can be obtained by using the horizontal $Z_{H}$ and the differential $Z_{D R}$ reflectivities than by using the reflectivity $Z$ alone. However, most dual polarization measurements made so far have been compared to individual raingage measurements for very short time intervals (a few minutes). These comparisons suffer from the fact that both measurements have very different sampling volumes and may not have the same statistical significance. Therefore, the other goal of this paper is to compare, for the shortest time intervals $\Delta t$ and highest spatial resolutions $\Delta x$ available from the gage network, the mean rainfall rate $R_{G}$ deduced from the gage data to that deduced from the radar measure- 
ments, either without $\left(R_{Z}\right)$ or with $\left(R_{D}\right)$ using the differential reflectivity $Z_{D R}$. The computation of the field values of the mean equivalent rainfall rate derived from the radar data is described in section 5 , and the quantitative comparisons are made in section 6 .

\section{Data description}

The present experiment has been conducted in the vicinity of Clermont-Ferrand (France) between May 1985 and August 1986. During this period, 48 precipitation events, including some very intense convective hailstorms (Husson et al. 1989) have been fully recorded.

\section{a. Raingage data}

The 14 one-minute tipping bucket raingages have a $1000 \mathrm{~cm}^{2}$ (2000 $\mathrm{cm}^{2}$ for two gages) sampling crosssectional area, giving a water height resolution of 0.2 $\mathrm{mm}(0.1 \mathrm{~mm})$. The tipping number is electronically recorded every minute and the time accuracy is of the order of a few seconds. As shown in Fig. 1, the network covers a $25 \mathrm{~km}^{2}$ area, lying between 5 and $10 \mathrm{~km}$ from the radar. In the following the rainfall fields are interpolated inside the solid line square in Fig. 1 and the comparisons are made within the dashed line square, in order to avoid extrapolating the gage data. For each selected time interval $\Delta t(5,15,30$ and $60 \mathrm{~min})$, and for each gage located at the point $M_{i}$, the mean rainfall rates $R\left(M_{i}, t_{k}\right)$ are computed for all time steps $t_{k}=(k$ - 1) $\Delta t+t_{0} ; k=1, \cdots, N$, as an average over the corresponding time interval $\Delta t$ centered around $t_{k}$. An example of the resulting time series is shown in Fig. 2 for the mean rainfall rates measured by three different gages during a convective storm that developed on 3 July 1986. On this figure a constant value, depending upon the gage number, has been added to the rainfall rate values in order to vertically separate the curves.

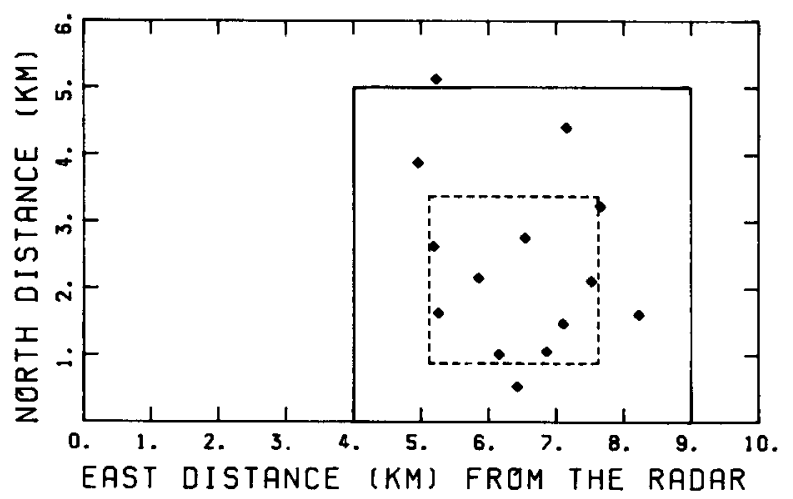

FIG. 1. Location of the 14 one-minute raingages with respect to the radar position. The rainfall fields are later drawn within the solid line square and the quantitative comparisons are made within the dashed line square, in order to avoid extrapolating the gage data.

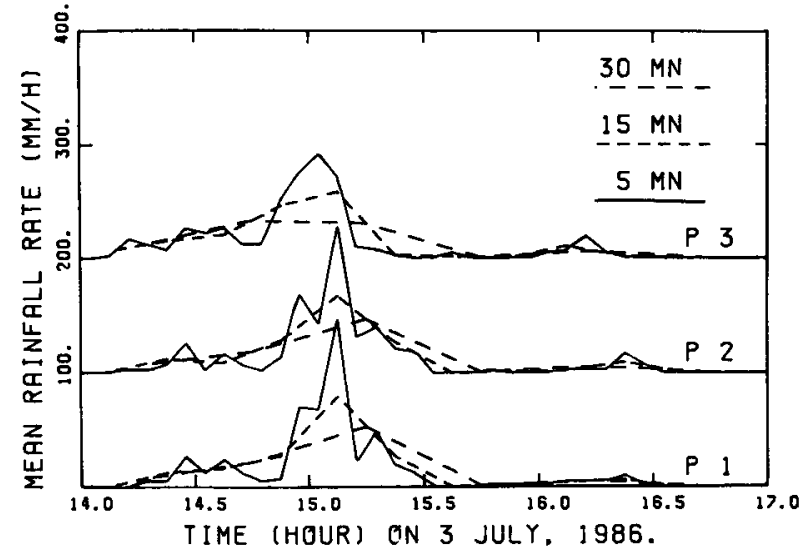

FIG. 2. Mean rainfall rates $R_{G}$, averaged over different time intervals ( $\Delta t=5,15$ and $30 \mathrm{~min}$ ), measured by three different gages on 3 July 1986, from 1400 to 1700 UTC. A constant value has been added to the rainfall rate values in order to vertically separate the curves corresponding to the different gages.

The peak values of the 5,15 and 30 -minute means vary, depending on the gage, from 44 to 147 , from 32 to 79 , and from 17 to $53 \mathrm{~mm} \mathrm{~h}^{-1}$, respectively. On this day, significant precipitations have lasted for more than one hour, giving a total water height between 26 and $45 \mathrm{~mm}$, depending upon the gage position. The displacement velocity of the storm is estimated, from successive radar images, to be 3.5 and $1.5 \mathrm{~m} \mathrm{~s}^{-1}$ toward the east and the south, respectively. Some hailstones have also been recorded at the ground (Husson et al. 1989) during this day.

\section{b. Dual polarization radar data}

The ANATOL radar (Pointin et al. 1988) is a 10$\mathrm{cm}$ dual polarization radar (Doviak and Zrnić 1984) that has a 1.8 degrees half power beam-width antenna and that rotates at about $8^{\circ} \mathrm{s}^{-1}$ (i.e., $1.3 \mathrm{rpm}$ ). The copolar return powers of the horizontally and vertically polarized pulses are averaged over their corresponding 64 alternative pulses and over four subgates within each gate. Every $0.256 \mathrm{~s}$, the values of the time, azimuth, elevation, and of the horizontal and vertical reflectivities in up to 1024 gates of $120 \mathrm{~m}$ width, are recorded on a magnetic tape. The zero value of $Z_{D R}$ has been regularly checked by recorded data in raining conditions with a vertically pointed antenna. The total gain of the $Z_{H}$ measurements has been obtained several times by integrating the equivalent rainfall rate, deduced from the radar data, and the raingage data recorded during one or two days in heavy widespread rainfalls (up to $250 \mathrm{~mm}$ in $48 \mathrm{~h}$ ).

In this experiment the data have been almost continuously recorded, either during PPI scans made at a constant low elevation ( 1 to 6 degrees), or during volume scans, made above the basin at elevation varying by 1.8-degree steps at each sweep, between 1 and 30 
degrees, and lasting about 6 minutes per volume scan. In the estimation of the radar derived rainfall rate only the data recorded below $1.5 \mathrm{~km}$ above the ground have been used, and most of them have been recorded below $1 \mathrm{~km}$. Since the biggest raindrops take less than $3 \mathrm{~min}-$ utes to fall from the top of the scanned volume to the ground and since the time interval $\Delta t$ used in the comparison is greater than 15 minutes (section 3 ), no correction has been made for the horizontal advection. Also, during this fall, important modifications of the drop size distribution could be induced by size sorting, by evaporation, by collisions, and so on (Austin 1987). However, no correction has been made since most of the radar data have been recorded below $1 \mathrm{~km}$ above the raingages.

\section{Time and space scale of rainfall fields}

For each selected time interval $\Delta t(5,15,30$ and 60 $\min )$, the intercorrelation coefficient $\rho_{\tau}\left(M_{i}, M_{j}\right)$ has been computed as a function of the time lag $\tau$, from the two time series of the mean rainfall rate values $R\left(M_{i}, t_{k}\right)$ and $R\left(M_{j}, t_{k}\right)$ of the two gages located at points $M_{i}$ and $M_{j}$, respectively. The time lag $\tau$ enables us to take into account the horizontal advection of the precipitating cloud from the first gage to the other one. The computation of this intercorrelation coefficient has been made either for each precipitation event, or over a whole month. In order to avoid the artificial increase of this coefficient due to long no-precipitation periods, a joint rain indicator $\delta_{k}$ has been introduced. For each lag time $\tau$ and for each gage pair $(i, j)$, it is defined as:

$$
\delta_{k}= \begin{cases}0, & \text { if } \quad R\left(M_{i}, t_{k}\right)=R\left(M_{j}, t_{k}+\tau\right)=0 \\ 0, & \text { if } t_{k}<t_{0} \\ & \text { or }\left(t_{k}+\tau\right)>T=t_{0}+(N-1) \Delta t \\ 1, & \text { else. }\end{cases}
$$

By using this rain indicator, the intercorrelation coefficient $\rho_{r}\left(M_{i}, M_{j}\right)$ is computed only for precipitating periods by:

$$
\begin{aligned}
\rho_{\tau}\left(M_{i}, M_{j}\right)= & \frac{1}{N_{T}} \frac{\sum_{k=1}^{N}\left[R\left(M_{i}, t_{k}\right) \delta_{k}-\mu\left(M_{i}\right)\right]}{\sigma\left(M_{i}\right)} \\
& \times \frac{\left[R\left(M_{j}, t_{k}+\tau\right) \delta_{k}-\mu\left(M_{j}\right)\right]}{\sigma\left(M_{j}\right)},
\end{aligned}
$$

where the mean and the variance values used in the previous equation are accordingly given by:

$$
\begin{aligned}
\mu\left(M_{i}\right) & =\frac{1}{N_{T}} \sum_{k=1}^{N} R\left(M_{i}, t_{k}\right) \delta_{k}, \\
\sigma^{2}\left(M_{i}\right) & =\frac{1}{N_{T}} \sum_{k=1}^{N}\left[R\left(M_{i}, t_{k}\right) \delta_{k}-\mu\left(M_{i}\right)\right]^{2},
\end{aligned}
$$

and where $N_{T}$ is the total number of time steps used in the evaluation of the intercorrelation coefficient:

$$
N_{T}=\sum_{k=1}^{N} \delta_{k}
$$

An example of the intercorrelation coefficients, computed for the different time intervals $\Delta t$ as a function of the time lag $\tau$, is shown in Fig. 3 for two gages; one of these gages is located at a distance of $2.88 \mathrm{~km}$ in an east-northeast direction from the other one. The rainfall data used for this figure are relative to the month of June 1986, during which several widespread and a few convective events have been advected over the area, generally toward the east. Figure 3 shows that, for a given time interval $\Delta t$, the intercorrelation coefficient $\rho_{\tau}\left(M_{i}, M_{j}\right)$ becomes less than 0.2 for time lags $\tau$ greater than 60 minutes, and it takes its maximum value for a null time lag, except for the 5-minute time interval. Furthermore, for a given time $\operatorname{lag} \tau$, it increases with the time interval $\Delta t$. These properties are verified for all gage pairs in the network, and result from the fact that a time of 15 minutes appears to be much less than the time needed for a precipitating cloud to cross the $5 \mathrm{~km}$ wide area. Therefore, the smallest time interval $\Delta t$ available for this network (Eddy 1976) can be searched for only through a study of what we call the neg-correlation coefficient $\omega\left(M_{i}, M_{j}\right)$, defined from the zero-lag intercorrelation coefficient $\rho_{0}\left(M_{i}, M_{j}\right)$ by

$$
\omega\left(M_{i}, M_{j}\right)=1-\rho_{0}\left(M_{i}, M_{j}\right) .
$$

The interest in this neg-correlation stems from the fact that, for ergodic, homogeneous, and stationary fields $Z(M)$, this neg-correlation is equal to the ratio, by the field variance, of the semivariogram $\gamma\left(M_{i}, M_{j}\right)$

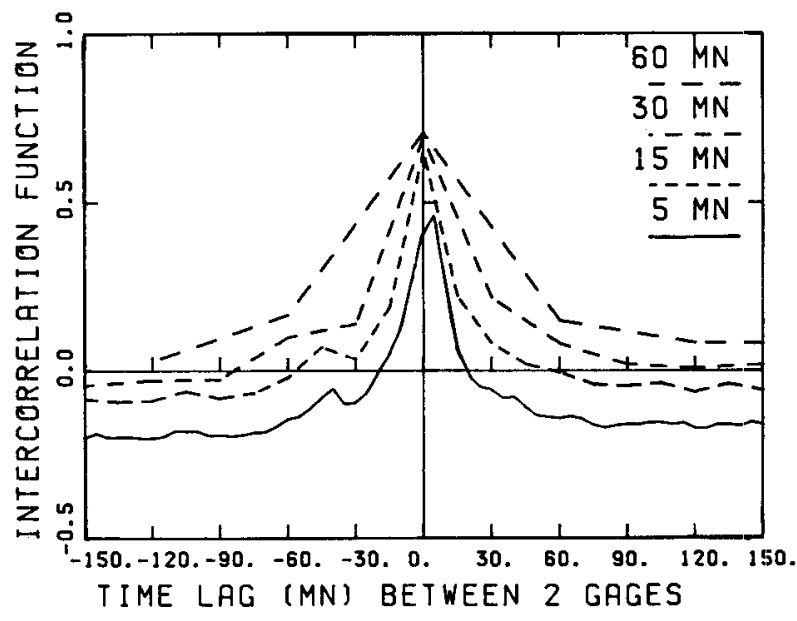

FIG. 3. Intercorrelation function $\rho_{\tau}\left(M_{i}, M_{j}\right)$ versus the time lag $\tau$ for the mean rainfall rate $R_{G}$, averaged over different time intervals ( $\Delta t=5,15,30$ and $60 \mathrm{~min}$ ), for two gages located at the points $M_{i}$ and $M_{j}$, which are separated by a distance of $2.88 \mathrm{~km}$, in an eastnortheast direction. 
(Matheron 1971; Creutin and Obled 1982), also called the structure function, and defined by the mathematical expectation of the squared difference between the values at the two points:

$$
\gamma\left(M_{i}, M_{j}\right)=\frac{1}{2} E\left\{\left[Z\left(M_{i}\right)-Z\left(M_{j}\right)\right]^{2}\right\} .
$$

Despite the fact that, particularly for the short time intervals, and for the small number of raingages used in this study, the observed rainfall field can hardly be considered as ergodic, homogeneous or stationary, we shall use the neg-correlation function in place of the semivariogram in the kriging interpolation technique (Matheron 1971; Creutin and Obled 1982) described in the next section.

The neg-correlation values for every gage pairs in the network are plotted versus the distance between the corresponding gages in Figs. 4 and 5, for the rainfall rate data relative to the months of June and April 1986, respectively. In these figures the different symbols indicate the time interval $\Delta t$ used in the computation of the correlogram values. Despite an appreciable scattering of the points, which decreases with the time interval $\Delta t$ and decreases for a less convective situation (April in Fig. 5 compared to June in Fig. 4), the data points are clustered along the curve of the neg-correlation function $\omega_{s}(h, \Delta t)$, defined, for each time in- terval (Eddy 1976), only as a function of the distance between the two gages. Indeed, for this small network, no clear dependence upon the relative gage orientation has been found, even for a 5-minute time interval for which the influence of the advection effects should have been the largest. For each time interval the coefficients $a, b$ and $h_{p}$ of a spherical function have been nonlinearly adjusted (Lybanon 1985):

$\omega_{s}(h, \Delta t)= \begin{cases}a+(b-a)\left[\frac{3}{2}\left(h / h_{p}\right)-\frac{1}{2}\left(h / h_{p}\right)^{3}\right] \\ b, \quad \text { otherwise, } & \text { if } h<h_{p}\end{cases}$

where $h_{p}$ is the range value beyond which the correlation takes the constant value $b$, and $a$ represents a discontinuity for short distances which reflects a white noise effect. Indeed, the comparison of collocated gages shows very large differences for short time intervals (Woodley et al. 1975), mainly due to very small scale inhomogeneities (turbulence). This white noise effect is generally larger for smaller time intervals and for widespread conditions than for convective ones. This last property results from the fact that, for widespread precipitations, the average tipping number is smaller

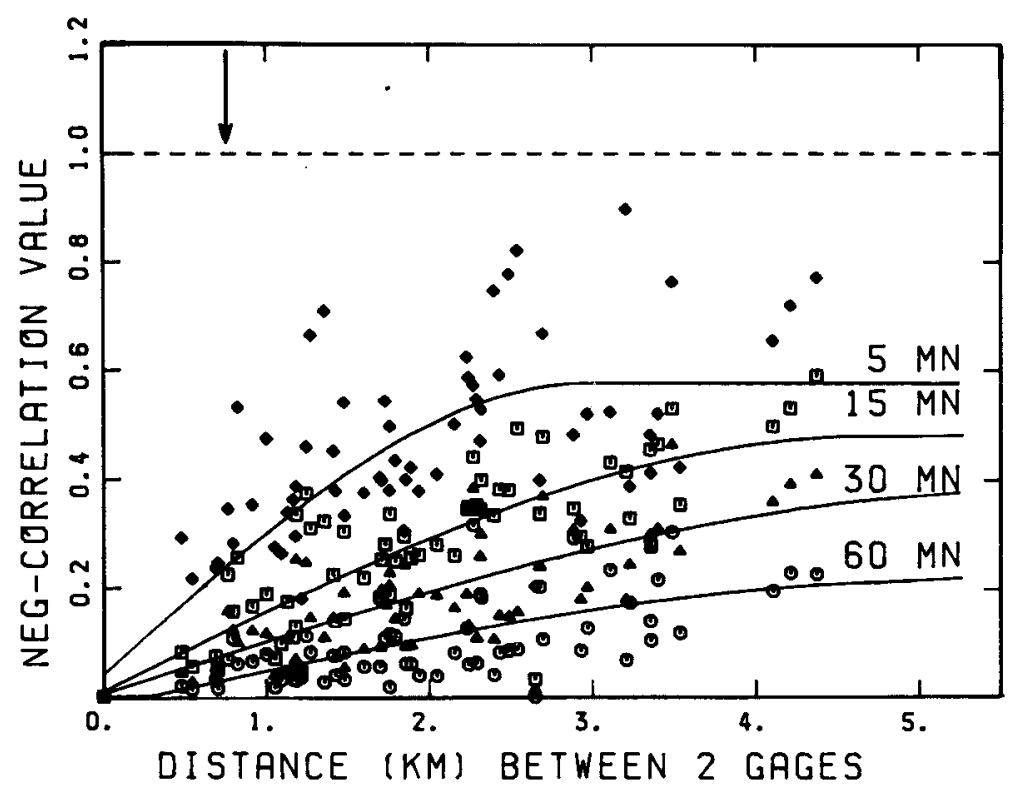

FIG. 4. Neg-correlation $\omega\left(M_{i}, M_{j}\right)=1-\rho_{0}\left(M_{i}, M_{j}\right)$ coefficients between the mean rainfall rate $R_{G}$ time series recorded during June 1986 by all gage pairs $\left(M_{i}, M_{j}\right)$ of the network, plotted versus the distance between the two gages of the pair. The different symbols refer to different time intervals $\Delta t(\hat{\diamond}=5 \mathrm{~min}, \square=15 \mathrm{~min}, \Delta=30 \mathrm{~min}, \odot$ $=60 \mathrm{~min}$ ) over which the mean rainfall rates are averaged. The solid lines represent the neg-correlation functions $\omega_{s}(h, \Delta t)$ adjusted from Eq. (8) and drawn versus the gage distance $h$, for the different time intervals $\Delta t$, and the dashed line indicates the null correlation. The vertical arrow at the top of the figure points to half the mean distance between the gages of the network. 


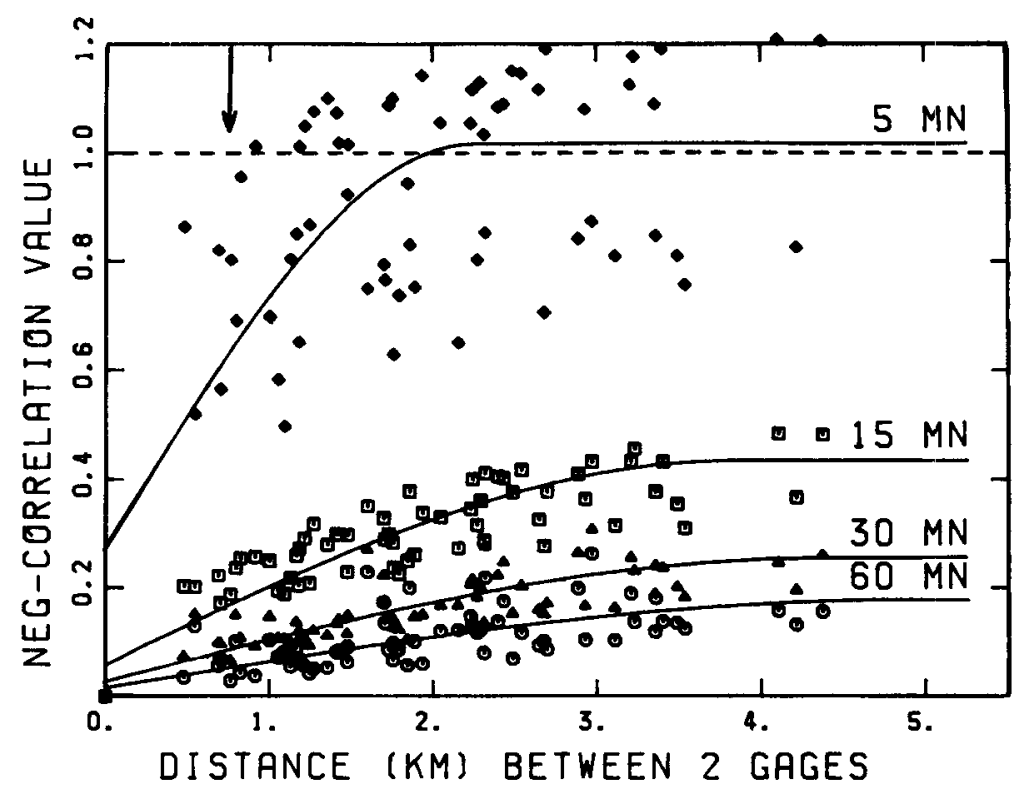

FIG. 5. The same as Fig. 4 for the gage data recorded during April 1986, corresponding to more widespread situations.

and the sampling errors are relatively larger (Woodley et al. 1975).

The large scattering of the points around the negcorrelation function may induce large errors in the spatial interpolation of the gage data, since each gage data is then representative of an area that is not well defined. This is especially true for the 5-minute data, which also show very small correlations (less than 0.70 , corresponding to $\omega>0.30)$ for distances $(0.75 \mathrm{~km})$ of the order of half of the mean distance $(1.5 \mathrm{~km})$ between gages in this network. This implies that, for this time interval, the data of any raingage cannot be statistically extended to the area that each gage is supposed to cover. However, for time intervals greater than 15 minutes, the correlation values are above 0.8 (corresponding to $\omega<0.20$ ) for distances shorter than half the network mean distance, suggesting that spatial interpolation may be statistically valid for these largest time intervals. As shown in Figs. 4 and 5, for hourly data, the correlation remains high for larger distances than for the 15-minute data, suggesting that the mean distance between gages could be of the order of $10 \mathrm{~km}$, at least for these precipitation conditions. This implies that the interpolation of hourly gage data may be statistically significant only if the gage density is above 1 gage per 78 square kilometers.

\section{Spatial interpolation of the raingage data}

For each time interval the gage data are spatially interpolated by using the kriging interpolation technique (Matheron 1971; Creutin and Obled 1982). The interpolated value $R_{G}\left(M, t_{k}\right)$ at any point $M$ is a linear combination of the $N$ measured values $R\left(M_{i}, t_{k}\right)$ at all gage points $M_{i}$ :

$$
R_{G}\left(M, t_{k}\right)=\sum_{i=1}^{N} \lambda_{i} R\left(M_{i}, t_{k}\right)
$$

The weighting coefficients $\lambda_{i}$ are the elements of the $N$ vector $\Lambda$, which is calculated from the matrix system:

$$
\left(\begin{array}{cc}
\Gamma & E \\
E^{T} & 0
\end{array}\right)\left(\begin{array}{l}
\Lambda \\
\mu
\end{array}\right)=\left(\begin{array}{c}
\Gamma_{0} \\
1
\end{array}\right)
$$

where $E^{T}=(1, \cdots, 1)$ is the transposed of the $E$ vector ( $N$ unitary vector) and $\mu$ is a scalar Lagrange multiplier that is introduced in order to ensure that the interpolated value is statistically unbiased. The elements of the $N$ vector $\Gamma_{0}$ (of the $N \times N$ matrix $\Gamma$, respectively) are equal to the neg-correlation between the interpolating point $M$ and the gage point $M_{i}$; i.e., $\omega_{s}\left(\left\|\overrightarrow{M M}_{i}\right\|, \Delta t\right)$ (to the neg-correlation between the gage stations $M_{i}$ and $M_{j}$; i.e., $\omega_{s}\left(\left\|\overrightarrow{M_{i} M_{j}}\right\|, \Delta t\right)$, respectively). The interpolated value $R_{G}\left(M, t_{k}\right)$ is computed at every center points of a regular grid which is included in the full line square drawn in Fig. 1, and with grid sizes $\Delta x=\Delta y$.

An example of the resulting field of the mean rainfall rate $R_{G}$ is shown in Fig. 6 for the 15-minute time interval between 1500 and 1515 UTC on 3 July 1986 and for grid sizes $\Delta x=\Delta y=0.25 \mathrm{~km}$. The maximum rainfall rate of $80 \mathrm{~mm} \mathrm{~h}^{-1}$ is reached at about $7.1 \mathrm{~km}$ east and $1.5 \mathrm{~km}$ north of the radar, where the raingage number 6 is located, and the minimum value of 7.3 $\mathrm{mm} \mathrm{h}^{-1}$ is reached on the north of the area. This in- 
terpolated 15 -minute mean rainfall field has a characteristic length scale greater than half the mean distance of the gage network. This results partly from the characteristic length of the true mean rainfall field and partly because of the smoothing effect of the neg-correlation function, particularly due to the discontinuity value $a$ of the white noise effect. Indeed, this discontinuity value $a$ represents a measure of the uncertainty of the point value. In order to decrease this uncertainty the kriging technique replaces this point value by a weighted mean between the value of the neighboring gages, and the value of the considered gage. Therefore, the larger this discontinuity value $a$, the smoother the mean field. The resulting characteristic length of the interpolated field is the determining factor for the choice of the interpolating grid sizes $\Delta x$ and $\Delta y$. For the time interval $\Delta t$ of 15 minutes, a choice of $0.5 \mathrm{~km}$ instead of $0.25 \mathrm{~km}$ gives almost the same interpolated field, while for a time interval of 1 hour, the grid size can be as large as $1 \mathrm{~km}$ without losing any details.

\section{Spatial average of the radar data}

Numerous authors have proposed $R-Z_{H}$ relationships of the form:

$$
Z_{H}=a R_{Z}^{b},
$$

where $R_{Z}\left(\mathrm{~mm} \mathrm{~h}^{-1}\right)$ is the equivalent rainfall rate derived from the radar measured reflectivity factor $Z_{H}$ $\left(\mathrm{mm}^{6} \mathrm{~m}^{-3}\right)$. Different relationships should be used in widespread and in convective conditions ( see Doviak 1983, or Austin 1987, among others, for discussions). In the following treatments, the chosen coefficients are, with the used units, $a=200, b=1.6$ for widespread conditions, and $a=486, b=1.37$ for convective conditions. Similarly, several authors have proposed $R-$ $\left(Z_{H}, Z_{D R}\right)$ relationships, either derived from theoretical or from disdrometer measured drop spectra (Seliga et al. 1981; Bringi et al. 1982; Ulbrich and Atlas 1984; Feingold and Levin 1987; Sachidananda and Zrnić 1987), assuming some form of the relationship between the raindrop axial ratio and the drop diameter (Pruppacher and Pitter 1971). In order to avoid a singular behavior for small $Z_{D R}$ values, we use the following relationship, very similar to that used by Seliga et al. (1981), for the equivalent rainfall rate $R_{D}$ derived from the radar measured horizontal $Z_{H}$ and differential $Z_{D R}$ reflectivities:

$$
R_{D}=\frac{a Z_{H}^{b}}{c+Z_{D R}^{d}},
$$

where the coefficients are $a=0.0033, b=0.98$, $c=0.55$ and $d=2.33$, when $R_{D}, Z_{H}$ and $Z_{D R}$ are expressed in $\mathrm{mm} \mathrm{h}^{-1}, \mathrm{~mm}^{6} \mathrm{~m}^{-3}$ and $\mathrm{dB}$, respectively. These coefficients have been nonlinearly adjusted (Lybanon 1985) by using Pruppacher and Pitter (1971) raindrop axial ratio relationship and 1419 drop spectra measured by two disdrometers every 5 minutes, during the most intense precipitation events that have appeared in all the ANATOL experiments of the last 4 years. This relationship adjusts very well (maximum and mean errors of 4.5 and $0.3 \mathrm{~mm} \mathrm{~h}^{-1}$, respectively) the rainfall rate values directly computed from each spectra, for values of up to $50 \mathrm{~mm} \mathrm{~h}^{-1}$. However, inside the clouds, the raindrop oscillation may change the axial ratio relationship (see Chandrasekar et al. 1988 for a complete discussion ) and this would modify the values of the coefficients in Eq. (12) to $a=0.0025, b$ $=0.97, c=0.59$ and $d=2.07$ for the Chandrasekar et al. (1988) relationship. Due to the small differences between these two sets of coefficients, the former set has been used.

In order to decrease the noise level, the measured values of the horizontal $Z_{H}$ and differential $Z_{D R}$ reflectivities are, for each recorded sequence, specifically filtered as functions of the radial distance. This special filter is based on the radial variations, obtained with a 0.12 or $0.24 \mathrm{~km}$ resolution, of the differential reflectivity $Z_{D R}$. These variations are low for cloud dominant measurements and high for ground clutter ones. The use of a threshold value for these variations is a very efficient way to detect the ground echo data that are not dominated by cloud values $\left(0 \leqslant Z_{D R} \leqslant 5 \mathrm{~dB}\right)$; the detected ground reflectivities $Z_{H}$ and $Z_{D R}$ are then set equal to zero. The filtered radar data are converted, by using either Eq. (11) or Eq. (12), in equivalent rainfall rate $R_{Z}$ or $R_{D}$, which are accumulated over all measurements made during the corresponding time interval $\Delta t$, and above each grid mesh of sizes $\Delta x=\Delta y$. It has been found that, for about $(0.3 \mathrm{~km})^{3}$ radar sampling volume, the time series of the equivalent rainfall rate above a fixed point have a time scale of about $10 \mathrm{~min}-$ utes. This means that an instantaneous radar measurement, made at short distance, is statistically representative of a one-minute average (correlation above 0.9 ), and that a perfect radar time coverate (RTC) of $100 \%$ of the basin can only be obtained if the antenna rotates at more than $1 \mathrm{rpm}$, as the ANATOL antenna does. From the recorded data, this RTC is estimated by the relative duration of the union of every oneminute interval centered at each instant that the radar beam passes over a fixed given point. Due to the scanning procedures used in the data collection, and to some necessary interruptions, the radar time coverage for the 15 -minute time intervals varies between $35 \%$ and $75 \%$. This RTC could be increased by taking into account the horizontal displacement of the clouds (Austin 1987) and interpolating between the radar images, but this has not yet been tested on the present dataset.

Examples of the resulting field of the mean equivalent rainfall rate, deduced from the radar data by using Eqs. (11) and (12), are shown in Figs. 7 and 8 respec- 


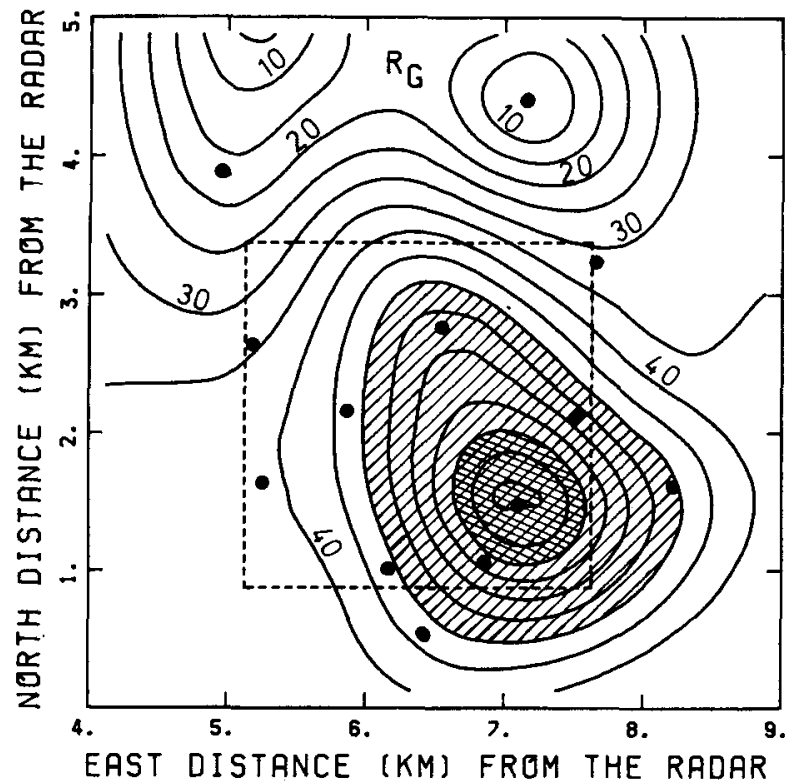

FIG. 6. Isolines of the mean rainfall rate $R_{G}$ interpolated from the 15-minute averaged gage data. The isolines are drawn every $5 \mathrm{~mm}$ $\mathrm{h}^{-1}$ and the area in which $R_{G}$ is greater than $50 \mathrm{~mm} \mathrm{~h}^{-1}$ is hatched. The small circles indicate the gage position and the dashed line square encloses the area in which the quantitative comparisons are made.

tively, for the same 15-minute time interval between 1500 and 1515 UTC on 3 July 1986, and for grid sizes $\Delta x=\Delta y=0.25 \mathrm{~km}$, as in Fig. 6. In Fig. 7 the maximum equivalent rainfall rate $R_{Z}$ of $74 \mathrm{~mm} \mathrm{~h}^{-1}$ is reached at about $7.9 \mathrm{~km}$ east and $1.2 \mathrm{~km}$ north of the radar (out-

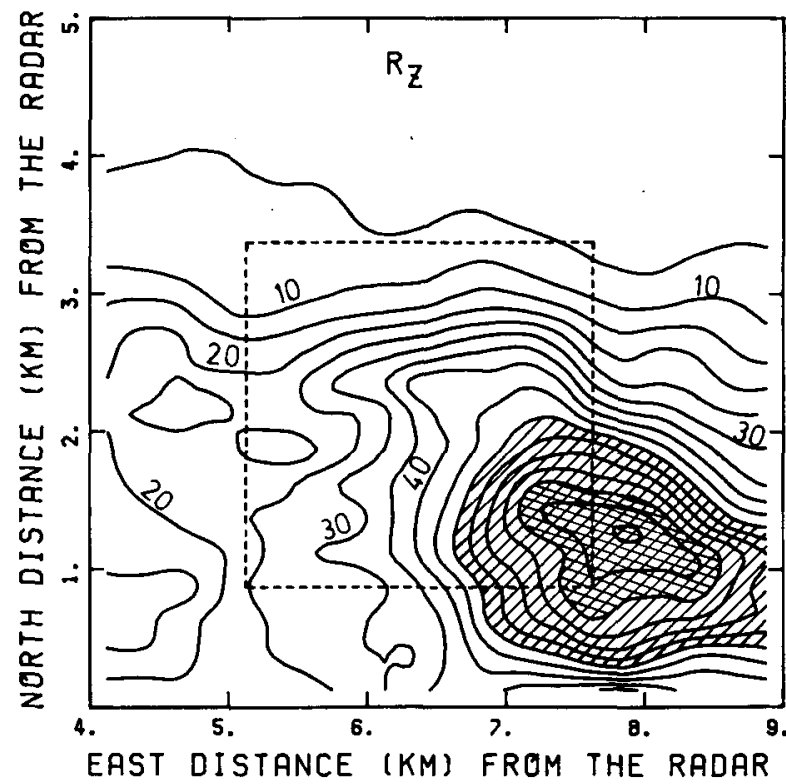

FiG. 7. The same as Fig. 6 for the mean rainfall rate $R_{Z}$ deduced through a $R-Z$ law from the radar data, i.e., brought forward without using the $Z_{D R}$ values. side of the gage polyhedral , as compared to the corresponding 7.1 and $1.5 \mathrm{~km}$ for the location of the $R_{G}$ maximum in Fig. 6. Similarly, the area in which the mean rainfall rate is above $50 \mathrm{~mm} \mathrm{~h}^{-1}$ is much smaller in Fig. 7 than in Fig. 6, and the minimum values are also smaller. These differences are respectively due to the fact that the gage network has probably not recorded the true maximum rainfall rate, and to the fact that the $R-Z_{H}$ relationship can lead to erroneous estirnations. These estimation errors are quantitatively analyzed in the next section. Further qualitative comparisons show that the $R_{Z}$ field in Fig. 7 has a smaller characteristic length scale than the $R_{G}$ field in Fig. 6 . It has been checked (Messaoud 1989) that the use of a coarser grid ( $\Delta x=\Delta y=0.5 \mathrm{~km}$ ) gives a very similar mean rainfall rate $R_{Z}$ field (not shown) to that of Fig. 7. This suggests that the spatial average over the area of sizes $\Delta x=\Delta y=0.25 \mathrm{~km}$ has induced no significant smoothing effects on the mean rainfall rate $R_{Z}$ field in Fig. 7. This implies that its length scale should be close to that of the true 15-minute mean rainfall rate $R_{m}$ field. On the other hand, the larger length scale of the $R_{G}$ field in Fig. 6 means that, even though the gage data provide a statistically significant estimate of the mean field, as shown in section 4, the gage density is not high enough to give the required spatial resolution of the true 15-minute mean $R_{m}$ field.

When the values of the differential reflectivity $Z_{D R}$ are used, as in Fig. 8, the maximum equivalent rainfall rate $R_{D}$ reaches $84 \mathrm{~mm} \mathrm{~h}^{-1}$ at about $7.5 \mathrm{~km}$ east and $1.2 \mathrm{~km}$ north of the radar and the area in which the

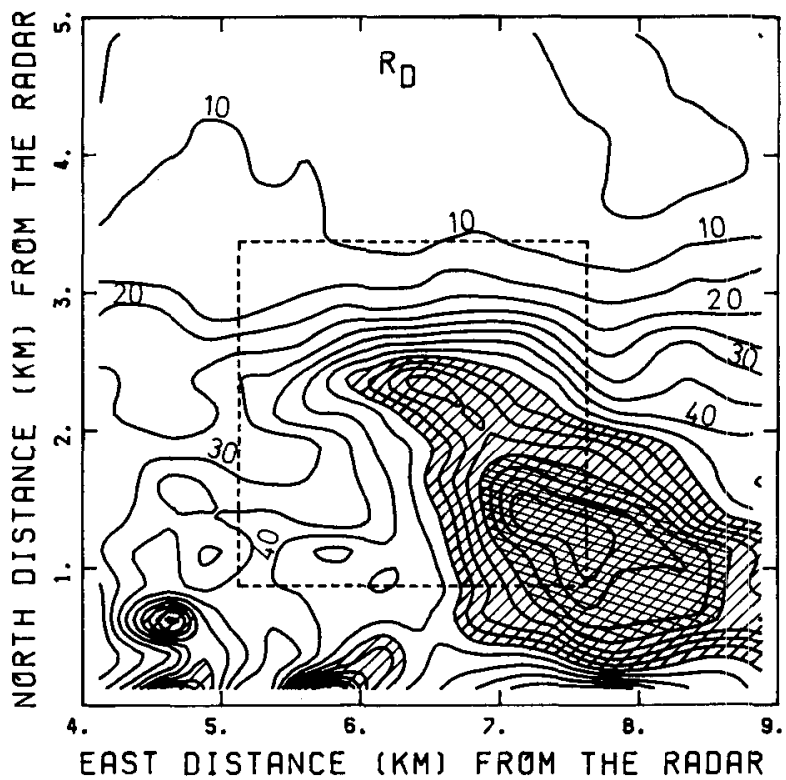

FIG. 8. The same as Fig. 6 for the mean rainfall rate $R_{D}$ deduced through a $R-Z_{H}, Z_{D R}$ law from the dual polarization radar data, including the differential reflectivity $Z_{D R}$ values. 
mean rainfall rate is above $50 \mathrm{~mm} \mathrm{~h}^{-1}$ is larger than the area of the $R_{Z}$ field, without covering the corresponding area of the measured $R_{G}$ field. This results from the fact that, for a given horizontal reflectivity $Z_{H}$ value, a lower value than usual, of the differential reflectivity $Z_{D R}$, induces a larger value of $R_{D}$ than of $R_{Z}$. This fact explains also why a small convective cell, in which the differential reflectivity $Z_{D R}$ is very low, shows up by a large value of $R_{D}$ on the left bottom corner in Fig. 8, outside of the raingage polyhedral. Because of the large spatial variability of the differential reflectivity $Z_{D R}$, induced by all the microphysical processes, the $R_{D}$ field in Fig. 8 has a slightly smaller characteristic length scale than the $R_{Z}$ field in Fig. 7, and a much smaller one than the $R_{G}$ field in Fig. 6 .

These qualitative comparisons show that the precipitation pattern is reasonably well reproduced by the three mean rainfall rate estimates $R_{G}, R_{Z}$ and $R_{D}$, even though the gage network may not have recorded the true maximum rainfall rate, located away from a raingage position, as suggested by the analysis of the radar data. Furthermore, in this experiment, the radar data, because of its good spatial resolution, can provide estimated rainfall rate $R_{Z}$ or $R_{D}$ fields with a smaller characteristic length scale than that of the $R_{G}$ field deduced from the gage data, despite the small mean distance $(1.5 \mathrm{~km})$ of the gage network.

\section{Quantitative comparisons}

For a given time interval $\Delta t$, more precise quantitative comparisons are made by plotting either the $R_{Z}$ values of the mean rainfall rate estimated from the radar data by using Eq. (11); i.e., without using the $Z_{D R}$ values, or the $R_{D}$ values estimated from the radar data by using Eq. (12), including the $Z_{D R}$ values, versus the corresponding $R_{G}$ values of the mean rainfall rate estimated from the gage data. These comparisons are obtained, for each time step $t_{k}$ of the precipitation events, between the corresponding mean values over each grid cell of area $\Delta x \cdot \Delta y$ located within the dashed line square in Fig. 1. This restriction avoids extrapolating the gage data outside of the raingage polyhedral. These comparisons for the $R_{Z}$ and $R_{D}$ values are illustrated by Figs. 9 and 10, respectively, for the same 15minute time interval between 1500 and 1515 UTC 3 July 1986 as used in Figs. 6, 7 and 8. In Figs. 9 and 10 , the circles correspond to the data of each grid cell containing a raingage, for which the interpolation and the smoothing of the gage data are minimum, and the dashed line indicates the least-squares linear relationship between the gage and the radar values for all grid cells.

In this example, as shown in Fig. 9, most of the $R_{Z}$ values are below the $R_{G}$ values, except for rainfall rates of the order of $70 \mathrm{~mm} \mathrm{~h}^{-1}$. The correlation coefficient $\rho$, given among other parameters in Table 1 for the different time steps of different days, is 0.89 in this example, and the root mean square error $\sigma$ (with respect to the least-squares relationship) is $8.6 \mathrm{~mm} \mathrm{~h}^{-1}$. This error could only be obtained if an appropriate $R-$ $Z_{H}$ relationship, similar to Eq. (11), is used, but the coefficients of this relationship would be different for each time step, as shown in Table 1. When using a fixed $R-Z_{H}$ relationship, although different for widespread and for convective conditions, the estimation error is of the order of the root mean square difference $E_{G Z}$ between the gage value $R_{G}$ and the radar derived value $R_{Z}$. This mean difference $E_{G Z}$ is always greater than the root mean square error $\sigma$, and is above 22 $\mathrm{mm} \mathrm{h}^{-1}$ in this case. The circles in Fig. 9, corresponding to grid cells containing a raingage, have a similar scattering than the other points that result from interpolated values. This suggests that the mean difference $E_{G Z}$ is mainly due to variations in the drop size distribution $N(D)$, and not to the interpolation process.

The comparison of the raingage $R_{G}$ and the radar $R_{Z}$ values from the other time steps, shown in Table 1 , indicates that for a time interval $\Delta t$ of $15 \mathrm{~min}$, the correlation coefficient is above 0.7 when the maximum rainfall rate is large (above $5 \mathrm{~mm} \mathrm{~h}^{-1}$ ) and when the radar time coverage is above $60 \%$. For small maximum rainfall rates the measurement errors due to the raingage tipping discretization $\left(0.8 \mathrm{~mm} \mathrm{~h}^{-1}\right.$ for a 15 -minute time interval) dominate the root mean square error $\sigma$. On the other hand, a small radar time coverage, particularly if the radar data are not evenly distributed over the time interval $\Delta t$, may prevent the radar from recording some intense transient precipitation events that last only a few minutes, as happened on 3 July 1986. For the analyzed dataset, the mean difference $E_{G Z}$ is always above $24 \%$ of the maximum mean rainfall rate during the corresponding time step, and may reach $30 \%$ when the radar coverage is not large enough. As shown in Fig. 9, the pointwise errors are mainly below $100 \%$, but they may be as large as $500 \%$ in some cases.

The comparison of the raingage $R_{G}$ values and the $R_{D}$ values, deduced from the radar data by using Eq. (12); i.e., including the differential reflectivity $Z_{D R}$ values, is illustrated in Fig. 10, for the same 15-minute time interval as in Figs. 6 to 9. In this figure the points are closer to the main diagonal, with a larger number above this line than in Fig. 9. This fact is confirmed by the comparison of Tables 1 and 2, which shows that for all time steps $t_{k}$ for which the radar time coverage (RTC) is above $50 \%$, the mean difference $E_{G D}$ between the gage value $R_{G}$ and the radar derived value $R_{D}$, using $Z_{D R}$, is smaller than $E_{G Z}$, which is the mean difference given by a conventional radar. For example, the data illustrated in Figs. 6 to 10 lead to mean difference values of $E_{G D}=17.0$ and $E_{G Z}=22.7 \mathrm{~mm} \mathrm{~h}^{-1}$, respectively. Therefore, the use of the differential reflectivity $Z_{D R}$ values has provided, in this case, a $25 \%$ decrease in the mean difference between the raingage and the radar 


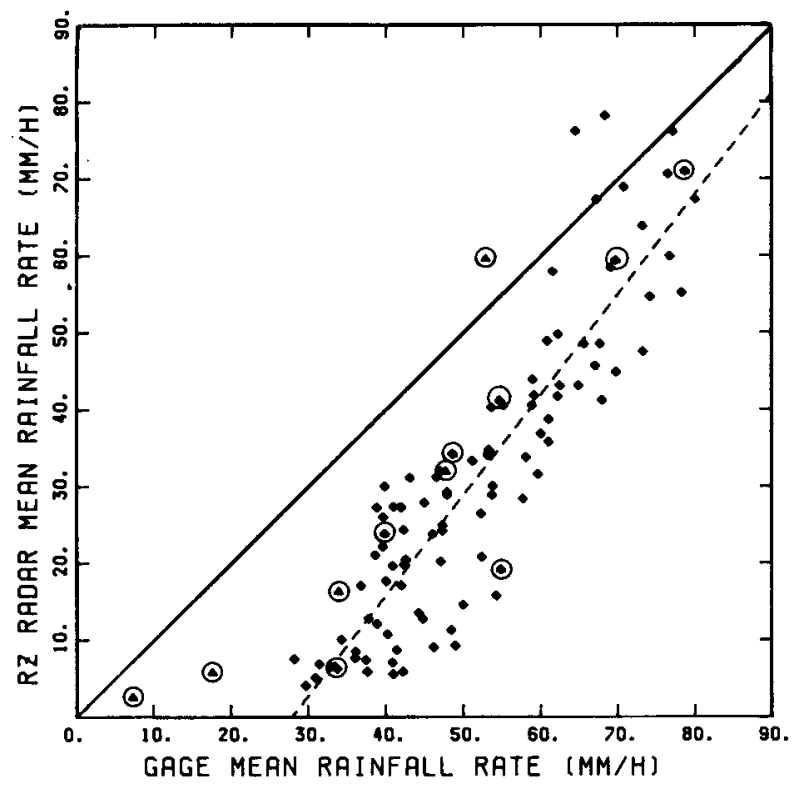

Fig. 9. Comparison between the mean values, over the 15 -minute time interval lasting from 1500 to 1515 UTC 3 July 1986, for the different grid meshes of sizes $\Delta x=\Delta y=0.25 \mathrm{~km}$, of the mean rainfall rate $R_{Z}$, deduced from the radar data, plotted versus the corresponding mean rainfall rate $R_{G}$, deduced from the gage data. The circles indicate the values belonging to grid meshes that contain one raingage. rainfall rate estimates, for a time interval $\Delta t=15 \mathrm{~min}$ utes. However, the correlation coefficient $\rho$ is sometimes slightly decreased, and the root mean square error $\sigma$ is generally increased when using the $Z_{D R}$ values. This larger scattering results from the smaller characteristic length scale of the $R_{D}$ field, as discussed at the end of section 5, than that of the gage interpolated $R_{G}$ field. When all the rainfall fields are computed on a larger grid $\Delta x=\Delta y=1.0 \mathrm{~km}$ (Messaoud 1989), implying a similar spatial smoothing, the correlation coefficients $\rho$ (not shown) are generally larger and the root mean square errors $\sigma$ are smaller when using the differential reflectivity $Z_{D R}$ values than for a conventional radar.

As shown in Table 1, for the longer time intervals $\Delta t$ of 30 and $60 \mathrm{~min}$, and for the time steps $t_{k}$ for which the $R_{G \text { max }}$ is large enough and for which the radar time coverage is large and evenly distributed, the correlation coefficient $\rho$ between the $R_{G}$ and the $R_{Z}$ values increases to above 0.96 and the root mean square error $E_{G Z}$ decreases from 22.7 to 12.8 and $6.5 \mathrm{~mm} \mathrm{~h}^{-1}$, respectively. As shown by the comparison of Tables 1 and 2, when the time interval $\Delta t$ increases to 30 minutes or to 1 hour, the improvement due to the use of the differential reflectivity $Z_{D R}$ becomes relatively less important, because the small scale microphysical inhomogeneities are smoothed out by the time averaging process.

TABLE 1. Results of the comparison between the mean rainfall rate values deduced from the gage data $R_{G}$ and that deduced from the radar data $R_{Z}$; i.e., without using the differential reflectivity $Z_{D R}$. For the different time intervals $\Delta t$ and for the different time steps $t_{k}$ ( $W$ is widespread, $C$ is convective precipitations), values of the maximum mean rainfall rate $R_{G \text { max }}$, of the least-squares coefficients $R_{Z}=a R_{G}$ $+b$, of the correlation coefficient $\rho$, of the root mean square error $\sigma$, of the mean difference $E_{G Z}=\operatorname{rms}\left(R_{G}-R_{Z}\right)$, and of the estimated radar time coverage $\mathrm{RTC}$.

\begin{tabular}{|c|c|c|c|c|c|c|c|}
\hline M/D/Y:Time steps & $\begin{array}{c}R_{G \max } \\
\left(\mathrm{mm} \mathrm{h}^{-1}\right)\end{array}$ & $a$ & $\begin{array}{c}b \\
\left(\mathrm{~mm} \mathrm{~h}^{-1}\right)\end{array}$ & $\rho$ & $\begin{array}{c}\sigma \\
\left(\mathrm{mm} \mathrm{h}^{-1}\right)\end{array}$ & $\begin{array}{c}E_{G Z} \\
\left(\mathrm{~mm} \mathrm{~h}^{-1}\right)\end{array}$ & $\begin{array}{c}\text { RTC } \\
(\%) \\
\end{array}$ \\
\hline \multicolumn{8}{|c|}{ Interval $\Delta t=15 \mathrm{~min}$} \\
\hline $\begin{array}{l}15 \text { June } 1986: 1830-1845 W \\
15 \text { June } 1986: 1845-1900 W \\
\text { 3 July } 1986: 1400-1415 C \\
\text { 3 July } 1986: 1415-1430 C \\
\text { 3 July } 1986: 1430-1445 C \\
\text { 3 July } 1986: 1445-1500 C \\
\text { 3 July } 1986: 1500-1515 C \\
\text { 3 July } 1986: 1515-1530 C \\
\text { 3 July } 1986: 1530-1545 C \\
\text { 3 July } 1986: 1545-1600 C\end{array}$ & $\begin{array}{r}39.1 \\
9.3 \\
8.5 \\
15.9 \\
20.4 \\
59.5 \\
80.0 \\
28.2 \\
2.9 \\
1.8\end{array}$ & $\begin{array}{r}0.50 \\
-0.20 \\
0.36 \\
0.50 \\
0.33 \\
0.03 \\
1.31 \\
0.61 \\
0.26 \\
0.35\end{array}$ & $\begin{array}{r}2.46 \\
1.80 \\
5.25 \\
2.86 \\
2.62 \\
33.65 \\
-36.40 \\
-1.39 \\
-1.97 \\
0.29\end{array}$ & $\begin{array}{r}0.83 \\
-0.57 \\
0.28 \\
0.29 \\
0.71 \\
0.04 \\
0.89 \\
0.94 \\
0.52 \\
0.42\end{array}$ & $\begin{array}{l}2.4 \\
0.2 \\
2.6 \\
2.9 \\
1.5 \\
9.2 \\
8.6 \\
1.7 \\
0.3 \\
0.3\end{array}$ & $\begin{array}{r}8.4 \\
4.1 \\
3.4 \\
5.1 \\
8.0 \\
14.0 \\
22.7 \\
6.9 \\
1.2 \\
0.4\end{array}$ & $\begin{array}{l}48 \\
10 \\
16 \\
55 \\
66 \\
33 \\
70 \\
40 \\
62 \\
74\end{array}$ \\
\hline \multicolumn{8}{|c|}{ Interval $\Delta t=30 \mathrm{~min}$} \\
\hline $\begin{array}{l}15 \text { June } 1986: 1830-1900 W \\
3 \text { July } 1986: 1400-1430 C \\
3 \text { July } 1986: 1430-1500 C \\
3 \text { July } 1986: 1500-1530 C \\
3 \text { July } 1986: 1530-1600 C\end{array}$ & $\begin{array}{r}23.2 \\
11.5 \\
36.9 \\
51.1 \\
1.4\end{array}$ & $\begin{array}{l}0.67 \\
0.15 \\
0.13 \\
1.28 \\
0.48\end{array}$ & $\begin{array}{r}1.05 \\
0.38 \\
8.76 \\
-20.78 \\
-0.03\end{array}$ & $\begin{array}{l}0.82 \\
0.26 \\
0.32 \\
0.96 \\
0.58\end{array}$ & $\begin{array}{l}1.8 \\
0.9 \\
2.2 \\
3.5 \\
0.2\end{array}$ & $\begin{array}{r}13.8 \\
8.2 \\
15.0 \\
12.8 \\
0.6\end{array}$ & $\begin{array}{l}29 \\
31 \\
54 \\
55 \\
68\end{array}$ \\
\hline \multicolumn{8}{|c|}{ Interval $\Delta t=60 \mathrm{~min}$} \\
\hline $\begin{array}{l}3 \text { July } 1986: 1400-1500 C \\
3 \text { July } 1986: 1500-1600 C\end{array}$ & $\begin{array}{l}24.0 \\
26.0\end{array}$ & $\begin{array}{l}0.15 \\
1.30\end{array}$ & $\begin{array}{r}-0.17 \\
-10.97\end{array}$ & $\begin{array}{l}0.44 \\
0.96\end{array}$ & $\begin{array}{l}1.0 \\
1.7\end{array}$ & $\begin{array}{r}15.9 \\
6.5\end{array}$ & $\begin{array}{l}42 \\
62\end{array}$ \\
\hline
\end{tabular}




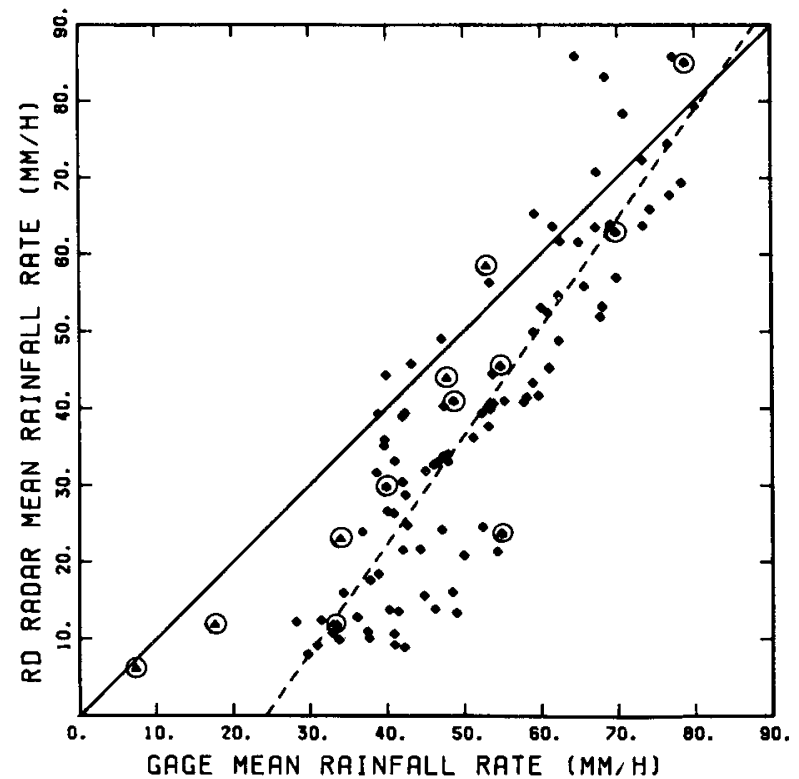

FiG. 10. As in Fig. 9 but for the comparison between the mean rainfall rate $R_{D}$, deduced from the dual polarization radar data, and the corresponding mean rainfall rate $R_{G}$, deduced from the gage data.

\section{Summary and conclusions}

Measurements of the rainfall rate have been made by a network of 14 one-minute raingages, located at less than $10 \mathrm{~km}$ from a dual polarization radar, during several widespread or convective precipitation events. The mean distance of the gages within the network is $1.5 \mathrm{~km}$, and the minimum and maximum distances between two gages are 0.48 and $4.97 \mathrm{~km}$ respectively.

Analyses have been made of the intercorrelation function of the time series of the mean rainfall rates measured by any two gages during consecutive time steps $t_{k}$ of size $\Delta t$. These analyses show that the intercorrelation function takes its maximum value for a zero time lag between the time series, for all time intervals $\Delta t$ greater than 5 minutes. Furthermore, the general tendency of the intercorrelation maximum to decrease with the distance between the two raingages (Eddy 1976; Creutin and Obled 1982; Creutin et al. 1988 ) is better observed as the time interval $\Delta t$ increases. The resulting spatial scale of the gage rainfall field increases as the time interval and, for this network, a high enough correlation $\left[\rho_{0}\left(M_{i}, M_{j}\right)\right.$ greater than 0.8 ] can only be obtained for a distance of the order of half the network mean distance, if the time interval $\Delta t$ is greater than 15 minutes. This implies that for time intervals smaller than 15 minutes, the mean rainfall rate measurements made by any raingage is not statistically representative of a mean value over the area that the gage is supposed to cover (Eddy 1976). Furthermore, this measured value is sullied by a white noise effect that is more important than the gage measurement error, and that is due to the small inhomo-

TABLE 2. Idem Table 1 for the mean rainfall rate $R_{D}$; i.e., by using the differential reflectivity $Z_{D R}$. Values of the least-squares coefficients $R_{D}=a R_{G}+b$, of the corresponding correlation coefficient $\rho$, of the root mean square error $\sigma$, and of the mean difference $E_{G D}=\operatorname{rms}\left(R_{G}-R_{D}\right)$.

\begin{tabular}{|c|c|c|c|c|c|c|c|}
\hline M/D/Y:Time steps & $\underset{\left(\mathrm{mm} \mathrm{h}^{-1}\right)}{R_{G \max }}$ & $a$ & $\begin{array}{c}b \\
\left(\mathrm{~mm} \mathrm{~h}^{-1}\right)\end{array}$ & $\rho$ & $\begin{array}{c}\sigma \\
\left(\mathrm{mm} \mathrm{h}^{-1}\right)\end{array}$ & $\begin{array}{c}E_{G D} \\
\left(\mathrm{~mm} \mathrm{~h}^{-1}\right)\end{array}$ & $\begin{array}{c}\text { RTC } \\
(\%)\end{array}$ \\
\hline \multicolumn{8}{|c|}{ Interval $\Delta t=15 \mathrm{~min}$} \\
\hline $\begin{array}{l}15 \text { June } 1986: 1830-1845 W \\
15 \text { June } 1986: 1845-1900 W \\
\text { 3 July } 1986: 1400-1415 C \\
\text { 3 July } 1986: 1415-1430 C \\
\text { 3 July } 1986: 1430-1445 C \\
\text { 3 July } 1986: 1445-1500 C \\
\text { 3 July } 1986: 1500-1515 C \\
\text { 3 July } 1986: 1515-1530 C \\
\text { 3 July } 1986: 1530-1545 C \\
\text { 3 July } 1986: 1545-1600 C\end{array}$ & $\begin{array}{r}39.1 \\
9.3 \\
8.5 \\
15.9 \\
20.4 \\
59.5 \\
80.0 \\
28.2 \\
2.9 \\
1.8\end{array}$ & $\begin{array}{r}0.78 \\
-0.22 \\
-0.01 \\
0.53 \\
0.34 \\
0.22 \\
1.41 \\
0.48 \\
0.33 \\
0.37\end{array}$ & $\begin{array}{r}5.46 \\
1.86 \\
11.64 \\
5.23 \\
3.82 \\
33.90 \\
-34.11 \\
-0.39 \\
0.20 \\
0.46\end{array}$ & $\begin{array}{r}0.88 \\
-0.41 \\
0.00 \\
0.25 \\
0.71 \\
0.32 \\
0.88 \\
0.93 \\
0.61 \\
0.44\end{array}$ & $\begin{array}{l}3.0 \\
0.3 \\
6.9 \\
3.5 \\
1.6 \\
6.5 \\
9.9 \\
1.5 \\
0.3 \\
0.3\end{array}$ & $\begin{array}{r}3.5 \\
4.2 \\
9.4 \\
3.9 \\
6.7 \\
10.6 \\
17.0 \\
7.3 \\
0.9 \\
0.4\end{array}$ & $\begin{array}{l}48 \\
10 \\
16 \\
55 \\
66 \\
33 \\
70 \\
40 \\
62 \\
74\end{array}$ \\
\hline \multicolumn{8}{|c|}{ Interval $\Delta t=30 \mathrm{~min}$} \\
\hline $\begin{array}{l}15 \text { June } 1986: 1830-1900 W \\
15 \text { June } 1986: 1400-1430 W \\
3 \text { July } 1986: 1430-1500 C \\
\text { 3 July } 1986: 1500-1530 C \\
3 \text { July } 1986: 1530-1600 C\end{array}$ & $\begin{array}{r}23.2 \\
11.5 \\
36.9 \\
51.1 \\
1.4\end{array}$ & $\begin{array}{r}0.93 \\
-0.05 \\
0.20 \\
1.31 \\
0.81\end{array}$ & $\begin{array}{r}2.95 \\
3.03 \\
15.26 \\
-16.91 \\
0.31\end{array}$ & $\begin{array}{r}0.88 \\
-0.05 \\
0.33 \\
0.94 \\
0.58\end{array}$ & $\begin{array}{l}1.9 \\
1.6 \\
3.1 \\
4.3 \\
0.4\end{array}$ & $\begin{array}{l}7.8 \\
7.6 \\
7.9 \\
8.9 \\
0.4\end{array}$ & $\begin{array}{l}29 \\
31 \\
54 \\
55 \\
68\end{array}$ \\
\hline \multicolumn{8}{|c|}{ Interval $\Delta t=60 \mathrm{~min}$} \\
\hline $\begin{array}{l}3 \text { July } 1986: 1400-1500 C \\
3 \text { July } 1986: 1500-1600 C\end{array}$ & $\begin{array}{l}24.0 \\
26.0\end{array}$ & $\begin{array}{l}0.10 \\
1.70\end{array}$ & $\begin{array}{r}1.46 \\
-12.38\end{array}$ & $\begin{array}{l}0.20 \\
0.92\end{array}$ & $\begin{array}{l}1.6 \\
3.1\end{array}$ & $\begin{array}{r}15.2 \\
4.5\end{array}$ & $\begin{array}{l}42 \\
62\end{array}$ \\
\hline
\end{tabular}


geneities of the true precipitation field. The effect of this white noise leads, by the kriging method, to a smoothing of the interpolated field that, however, decreases as the time interval $\Delta t$ increases.

As a consequence of these analyses, the mean rainfall field has been computed from the gage data by using the kriging interpolation techniques for different time steps of size $\Delta t$ greater or equal to 15 minutes. For the same time steps, the mean rainfall field has also been estimated from the radar data, either without, or with using the differential reflectivity $Z_{D R}$ values. The qualitative comparisons between the estimated fields show that the precipitation pattern is reasonably well reproduced by the three estimates, and that the characteristic length scale of the mean rainfall rate field estimated from the radar data without using $Z_{D R}$ is smaller than that estimated from the raingage data. However, due to the small scale microphysical inhomogeneities measured by a dual polarization radar, the smallest length scale of the estimated precipitation field is obtained by using the differential reflectivity $Z_{D R}$ values.

More precise comparisons between the mean rainfall fields show that the correlation between the $R_{G}$ values, deduced from the gage data, and the $R_{Z}$ values, deduced from the radar data without using the $Z_{D R}$ values, is above 0.7 when the mean rainfall rate values are large, and when the radar time coverage is above $50 \%$. The mean difference between the corresponding $R_{G}$ and $R_{Z}$ values is of the order of $25 \%$ of the maximum rainfall rate values. When using the $Z_{D R}$ values, the corresponding mean difference decreases to $20 \%$, implying that the use of the $Z_{D R}$ values does improve, in this case, the estimation of the mean rainfall field for small time intervals.

For larger time intervals ( 1 hour or more), this improvement appears to be relatively less important because the small scale inhomogeneities are smoothed out by the averaging process. On the contrary, for smaller time intervals $(\Delta t<15 \mathrm{~min}$ ), the differential reflectivity $Z_{D R}$ gives valuable information on small scale microphysical heterogeneities, but it has not been possible to really evaluate the improvement that the $Z_{D R}$ values can bring to the quantitative estimation of the short-time mean rainfall rate. This impossibility results from the poor estimation of the true mean rainfall rate values that can be obtained, for these short time intervals, from the data of the raingage network that, despite a gage mean distance of $1.5 \mathrm{~km}$, appears not quite dense enough for this purpose. Experiments are now planned in order to obtain accurate rainfall rate measurements at the ground that could be statistically representative for these short time intervals.

Acknowledgments. The experiments have been carried out under the French Ministère de la Recherche et de la Technologie (M.R.T.) Contract 84F 0497, and with the partial support of the "Atmosphère Météo- rologique" program committee of the Centre National de la Recherche Scientifique (C.N.R.S.), and of the Groupement National d'Êtudes des Fléaux Atmosphériques (G.N.E.F.A.). The authors are indebted to all campaign participants, to J. Fournet-Fayard, R. Pejoux, and F. Besserve for their help in the data treatments, and to O. Guillot and J. Squarise for editing this manuscript. Stimulating discussions with Drs. D. Creutin, H. Andrieu and D. Ramond, and with Prof. C. Obled are gratefully acknowledged. We thank the reviewers for their comments, which helped improve the manuscript.

\section{REFERENCES}

Austin, P. M., 1987: Relation between measured radar reflectivity and surface rainfall. Mon. Wea. Rev., 115, 1053-1070.

Barnston, A. G., and J. L. Thomas, 1983: Rainfall measurement accuracy in FACE: A comparison of gage and radar rainfalls. J. Climate Appl. Meteor., 22, 2038-2052.

Bringi, V. N., T. A. Seliga and E. A. Mueller, 1982: First comparisons of rainfall rates derived from radar differential reflectivity and disdrometer measurements. I.E.E.E. Trans. Geosci. Remote Sens., 20, 201-204.

Chandrasekar, V., and V. N. Bringi, 1987: Simulation of radar reflectivity and surface measurements of rainfall. J. Atmos. Oceanic Technol., 4, 464-478.

_- W. A. Cooper and V. N. Bringi, 1988: Axis ratios and oscillations of raindrops. J. Atmos. Sci., 45, 1323-1333.

Creutin, J. D., and C. Obled, 1982: Objective analysis and mapping techniques for rainfall fields: An objective comparison. Water Resour. Res., 18, 413-431.

— G. Delrieu and T. Lebel, 1988: Rain measurement by raingageradar combination: A geostatistical approach. J. Atmos. Oceanic Technol., 5, 102-115.

Doviak, R. J., 1983: A survey of radar rain measurement techniques. J. Climate Appl. Meteor., 22, 832-849.

— vations. Academic Press, $458 \mathrm{pp}$.

Eddy, A., 1976: Optimal raingage densities and accumulation tirnes: A decision-making procedure. J. Appl. Meteor., 15, 962-971.

Feingold, G., and Z. Levin, 1987: Application of the lognormal raindrop distribution to differential reflectivity radar measurement $\left(Z_{D R}\right)$. J. Atmos. Oceanic Technol., 4, 377-382.

Goddard, J. W. F., S. M. Cherry and V. N. Bringi, 1982: Comparison of dual polarization radar measurements of rain with groundbased disdrometer measurements. J. Appl. Meteor., 21, 252256.

Hall, M. P. M., S. M. Cherry, J. W. F. Goddard and G. R. Kennedy, 1980: Rain-drop sizes and rainfall rate measured by dual polarization radar. Nature, 285, 195-198.

Huff, F. A., 1970: Sampling errors in measurement of mean precipitation. J. Appl. Meteor., 9, 35-44.

Husson, D., Y. Pointin and D. Ramond, 1989: Discremination between hail and rain precipitation types from dual polarization radar, raingage and hailpad data. J. Theor. Appl. Climate, 40, 201-207.

Illingworth, A. J., J. W. F. Goddard and S. M. Cherry, 1987: Polarization radar studies of precipitation development in convective storms. Quart. J. Roy. Meteor. Soc., 113, 469-489.

Jameson, A. R., 1983: Microphysical interpretation of multi-parameter radar measurements in rain. Part I: Interpretation of polarization measurements and estimation of raindrop shapes. $J$. Atmos. Sci., 40, 1792-1802.

Lybanon, M., 1985: A simple generalized least-squares algorithm, Comput. Geosci., 11, 501-508. 
Matheron, G., 1971: The Theory of Regionalized Variables and its Applications. Ecole des Mines, Cahier 5, $211 \mathrm{pp.}$

Messaoud, M., 1989: Hydrologie aux fines échelles de temps et d'espace à partir des données de pluviomètres et d'un radar météorologique. Thèse de l'Université de Clermont-Ferrand.

Pointin, Y., D. Ramond and J. Fournet-Fayard, 1988: Radar differential reflectivity $Z_{D R}$ : A real-case evaluation of errors induced by antenna characteristics. J. Atmos. Oceanic Technol., 5, 416423.

Pruppacher, H. R., and R. L. Pitter, 1971: A semi-empirical determination of the shape of cloud and rain drops. J. Atmos. Sci., 28, 86-94.

Sachidananda, M., and D. S. Zrnić, 1987: Rain rate estimates from differential polarization measurements. J. Atmos. Oceanic Technol., 4, 588-598.

Seliga, T. A., and V. N. Bringi, 1976: Potential use of radar differential reflectivity measurements at orthogonal polarizations for measuring precipitation. J. Appl. Meteor., 15, 69-76.
— , V. N. Bringi and H. H. Al-Khatib, 1981: A preliminary study of comparative measurements of rainfall rate using the differential reflectivity technique and a raingage network. $J . A p p l$. Meteor., 20, 1362-1368.

_- K. Aydin and H. Direskeneli, 1986: Disdrometer measurements during an intense rainfall event in Central Illinois: Implications for differential reflectivity radar observations. J. Climate Appl. Meteor., 25, 835-846.

Silverman, B. A., L. K. Rogers and D. Dahl, 1981: On the sampling variance of raingage networks. $J$. Appl. Meteor., 20, 1468-1478.

Ulbrich, C. W., and D. Atlas, 1984: Assessment of the contribution of differential polarization to improved rainfall measurements. Radio. Sci., 19, 49-57.

Wilson, J. W., and E. A. Brandes, 1979: Radar measurement of rainfall-A summary. Bull. Amer. Meteor. Soc., 60, 1048-1058.

Woodley, W. L., A. R. Olsen, A. Herndon and V. Wiggert, 1975: Comparison of gage and radar methods of convective rain measurement. J. Appl. Meteor., 14, 909-928. 